\title{
Carotenoid Pigments Encapsulation: Fundamentals, Techniques and Recent Trends
}

\author{
Diego T. Santos and M. Angela A. Meireles*
}

LAboratory of Supercritical Technology: Extraction, Fractionation, and Identification of vegetable extracts (LASEFI), Department of Food Engineering (DEA), University of Campinas (UNICAMP), Rua Monteiro Lobato, 80, Cid. Universitária Zeferino Vaz, 13083-862, Campinas - SP, Brazil

\begin{abstract}
Supercritical fluids have become an attractive alternative due to environmentally friendly solvents. The methods that use supercritical fluids can be conveniently used for various applications such as extraction, reactions, particle formation and encapsulation. For encapsulation purposes, the processing conditions given by supercritical technology have important advantages over other methods that include harsh treatments with regard to $\mathrm{pH}$, temperature, light, the use of organic solvents, etc. Unstable functional pigments such as carotenoids extracted from natural sources have been encapsulated to overcome instability problem. Thus, the most used techniques applicable to this intention are described and discussed in this review as well the recent advances and recent trends in this topic that involves the use of supercritical fluids.
\end{abstract}

Keywords: Encapsulation, unstable functional pigments, carotenoids, supercritical fluids.

\section{INTRODUCTION}

Encapsulation is defined as a technology of packaging solids, liquids, or gaseous materials in matrices that can release their contents at controlled rates under specific conditions. The encapsulation technology has been used by the food industry for more than 60 years [1].

Protective encapsulation of food ingredients, enzymes, cells or other functional compounds may be thus achieved in small capsules of different nature. The main aim of encapsulation in the food area is to protect sensitive food components from moisture, oxidation, heat, light or extreme conditions during processing in an effort to increase their shelf life, or to mask component attributes, as undesirable flavours, to meet consumer requests for organoleptic quality and functionality. Furthermore, an optimized design of capsules, choosing the best encapsulation process and conditions, might provide a controlled release of active compounds during processing or storage [2].

In the last years, encapsulation has received increasingly growing attention resulting in a great number of applications in industry, agriculture, medicine, pharmacy and biotechnology. Diverse techniques have been studied and employed to form the desired capsules, including spray drying, liposome entrapment, coacervation, gelation, emulsion phase separation, etc [3]. Some of the most used techniques are described and discussed in this review. In addition, this paper gives an overview of the recent advances in the various encapsulation techniques applicable for stabilizing unstable functional pigments, such as, carotenoids from natural sources. Finally

*Address correspondence to this author at the laboratory of Supercritical Technology: Extraction, Fractionation, and Identification of vegetable extracts (LASEFI), Department of Food Engineering (DEA), University of Campinas (UNICAMP), Rua Monteiro Lobato, 80, Cid. Universitária Zeferino Vaz, 13083-862, Campinas - SP, Brazil; Tel: 00551935214033;

E-amil: meireles@fea.unicamp.br a discussion about the recent trends in this topic that involves the use of supercritical fluids instead of conventional solvents will be debated.

\section{ENCAPSULATION CONCEPT}

In general the purpose of encapsulation is to protect its contents from the environment which can be destructive while allowing small molecules to pass in and out of the membrane. According to Jizomoto and coworkers the encapsulation concept has its origin in the idealization of the cell model, in which the nucleus is involved by a semi-permeable membrane that protects it from the external medium and also controls the entrance and exit of substances. Other natural examples include birds and reptile egg shells, plant seeds, fruit and vegetable skins, seashells, etc [4].

The encapsulation process involves coating or entrapment of a material, usually a liquid but can be a solid or gas, or a mixture into another material. This material is also known as the core material. The coating material can also be called the capsule, wall material, membrane, carrier or shell [5].

The first applications of encapsulation were done in 1954 in the photography industry to produce pressure-sensitive dye capsules for the manufacturing of carbonless copying paper, since then, along the last decades encapsulation processes were developed and used in a variety of industries [6, 7]. In the food industry, diverse encapsulation techniques have been applied to protect unstable compounds, such as, flavours, pigments, vitamins, enzymes, microorganisms, and others [8].

\section{ENCAPSULATION OF UNSTABLE FUNCIONAL PIGMENTS}

Epidemiological evidences suggest that a diet rich in fruits and vegetables plays an important role in reducing the 
Table 1. Encapsulation Processes Division Forms Adopted by Some Reseachers

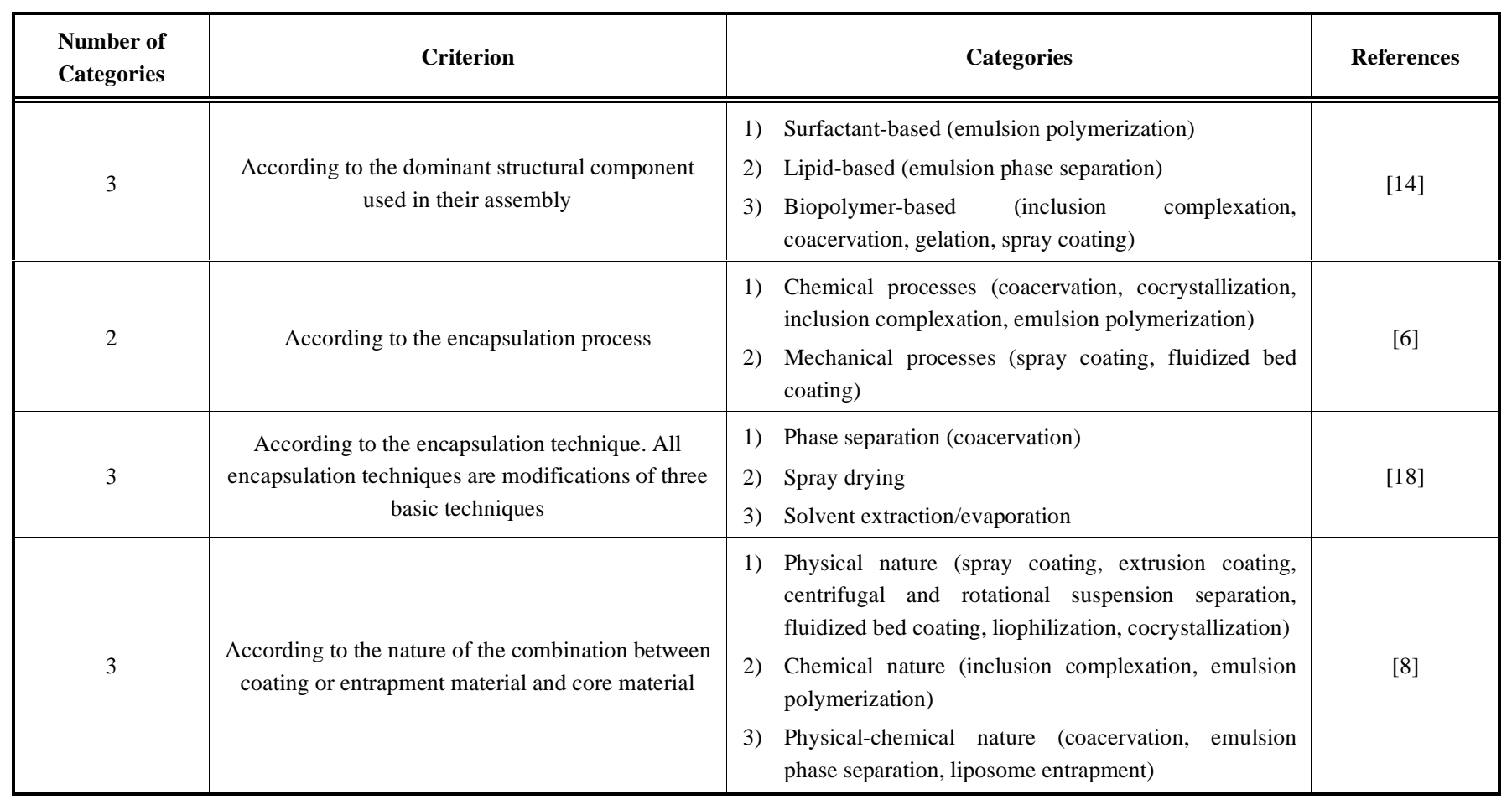

incidence of many diseases. The reason of this accomplishment can be the coloration of these foods, in general, a rich source of many antioxidants [9].

The increasing concern of consumers over the use of synthetic additives in products has pushed the food, pharmaceutical and cosmetic industries toward replacing these synthetic additives by natural products. However, difficulties may be encountered due to the instability of these compounds. An example are natural pigments with functional properties such as carotenoids, the most common group of pigments in nature [10].

In order to overcome the instability problem of these bioactive compounds, which results in restricted commercial applications, encapsulation has become an important tool, helping to increase shelf life and protecting the biological properties of the material [11]. Moreover encapsulation allows the controlled release of these functional pigments under desired conditions, for instance when ingested in the body [5].

\section{CAROTENOIDS}

Carotenoids significance is not only due to their colorant property, they also are very important for health. This compound is source of vitamin A and a precursor of important chemicals responsible for the flavor of foods and the fragrance of flowers. It shows important biologic activities associated with antioxidant properties, such as strengthening the immune system, decreasing the risk of degenerative illnesses such as cancer, preventing the risk of cardiovascular disease, preventing macular degeneration, and reducing the risk of cataracts $[12,13]$.

Carotenoid pigments are a diverse group of lipophilic compounds that contribute to the yellow to red colors of many foods. They are polyenes consisting of 3 to 13 conju- gated double bonds and in some cases 6 carbon ring structures at one or both ends of the molecule. The most common carotenoid types are $\beta$-Carotene, lycopene, lutein, and zeaxanthin [14].

Unstable carotenoids have their oxidative degradation triggered by light, temperature and/or extreme $\mathrm{pH}$ in the presence of oxygen. To improve their stability to oxidation different encapsulation techniques have been studied, resulting in a relative success and increasing additionally the dissolution rate of these lipossoluble compounds in water [15, $16]$.

\section{ENCAPSULATION TECHNIQUES}

Diverse techniques have been studied and employed to form the capsules in different industries, including spray coating: spray drying, spray chilling, spray cooling; extrusion coating; fluidized bed coating; liposome entrapment; simple and complex coacervation; inclusion complexation; emulsion polymerization; centrifugal and rotational suspension separation; thermal and ionic gelation; emulsion phase separation; liophilization; cocrystallization; etc $[1,3,17]$.

For convenience some scientists have divided the structured delivery systems and, consequently, the encapsulation processes in different forms. Table $\mathbf{1}$ shows the most frequently division forms adopted.

In this review paper will be assumed that the capsules can be prepared by various techniques, which feature that partly competing, partly complementary characteristics and many encapsulation processes are modifications of basic conventional techniques. Due to its high coverage the division form based on the nature of the combination between coating or entrapment material (called also as wall material or carrier material) and core material will be adopted in this review. Then, the three encapsulatipon categories: based on 
Physical nature, Chemical nature and Physical-chemical nature will be described and discussed below in order to demonstrate the recent advances/modification in some of the various encapsulation techniques that can be applicable for stabilizing unstable carotenoid pigments.

\section{ENCAPSULATION TECHNIQUES BASED ON PHYSICAL NATURE COMBINATION BETWEEN COATING MATERIAL AND CORE MATERIAL}

Among the encapsulation physical methods, some examples are: spray coating: spray drying, spray cooling/chilling; extrusion coating, centrifugal and rotational suspension separation, fluidized bed coating, liophilization, cocrystallization, etc [8].

In this paper, due to their higher aplicability especial attention will be given to the encapsulation techniques spray coating and spray drying. In the section Advantages and Limitations of the Conventional Encapsulation Methods Applicable for Stabilizing Carotenoid Pigments the other techniques will be rapidly discussed.

\section{Spray Coating}

The spray coating process involves the dispersion of the substance to be encapsulated in a coating or entrapment material, followed by atomization and spraying of the mixture into a chamber. When the atomization is done when a hot fluid desiccant (air) is passing into the chamber the spray coating process is called by spray drying and when the air desiccant is cold the process is called by spray cooling/chilling. After pass to the chamber the resulting capsules are then transported to a cyclone separator for recovery [19].

Another difference between spray drying and spray cooling/chilling is that in the last one there is generally no water to be evaporated. There is emulsification of the compounds into molten wall materials, followed by atomization to disperse droplets from the feedstock [20]. Although spray cooling and spray chilling are not the same technique, differing slightly only in the vessel temperature in which the coating material is sprayed [21], due to their similarity in this work they were grouped.

Spray drying is a commercial process widely used in large-scale production of encapsulated compounds. The merit of the process is due to several factors: high availability of equipment, low process cost, wide choice of coating or entrapment material, good encapsulation efficiency, good stability of the finished product, and large-scale production in continuous mode [22].

Spray drying is relatively simple and of high throughput but should not be used for highly temperature-sensitive compounds. To this kind of compounds, such as vitamins, enzimes, flavours, pigments, essential oils and others, spray cooling/chilling may be an appropriate method [8, 19]. Moreover, control of the particle size in the spray coating is difficult, and yields for small batches are moderate [23].

\section{Extrusion Coating}

According to Madene and coworkers the two major encapsulation industrial processes are spray drying and extrusion coating [6]. However, to food compounds the encapsu- lation by extrusion is a relatively new process compared to spray drying [1].

The advantage of this method is that the material is totally surrounded by the wall material and that any residual core is washed from the outside. Owing to this benefit this encapsulation method is called by some authors true or glass encapsulation [3].

Extrusion coating can be organized in two types: simple extrusion and centrifugal extrusion. In general, the process involves forcing a core material in a molten wall material mass through a die (laboratory scale) or a series of dies of a desired cross-section into a bath of desiccant liquid. The coating material hardens on contacting the liquid, entrapping the active substances. Then the extruded filaments are separated from the liquid bath, dried, and sized [12].

Basically, the difference between simple extrusion and centrifugal extrusion procedures is that in the last one the nozzle used is not a simple nozzle (the nozzle has a coaxial opening). Centrifugal extrusion is a liquid coextrusion process utilizing nozzles consisting of concentric orifice located on the outer circumference of a rotating cylinder. The core and the carrier materials are fed through, respectively, the inner and outer opening. The core and the coat fluids must be immiscible. At the tip of the coaxial nozzle the two fluids form a unified jet flow by centrifugal force, which is responsible to form the droplets [24].

In order to optimize the centrifugal extrusion coating some researchers are studying the recycle of the excess coating fluid from the centrifugal extrusion, while the resulting capsules are hardened. This modified process has been called by recycling centrifugal extraction [25]. However, the major problem of this method is related to the difficulty of obtaining capsules in extremely viscous carrier material melts [26].

\section{ENCAPSULATION TECHNIQUES BASED ON CHEMICAL NATURE COMBINATION BETWEEN COATING MATERIAL AND CORE MATERIAL}

According Jackson and Lee (1991) there are only two encapsulation chemical methods: inclusion complexation and emulsion polymerization [8]. The last one, also called by interfacial polymerization, will not be presented in this paper, spite of it been a well established method it is most used to trap inorganic particles and not necessarily improve their stability [27].

\section{Inclusion Complexation}

Inclusion complexation or molecular inclusion is called the encapsulation process that uses $\beta$-cyclodextrin molecular conformation to entrap any core material. A typical application is the protection of unstable and high added value specially flavours [28], but recently diverse bioactive compounds have been encapsulated by this technique [29].

The external part of the $\beta$-cyclodextrin molecule is hydrophilic, whereas the internal part (central cavity) is hydrophobic. Some particular molecules, which are apolar and have suitable molecular dimensions to fit inside the cavity, can be entrapped through a hydrophobic interaction. The mechanism involved in this method is based on the replacement of water molecules by less polar molecules [30]. 
Comparing the inclusion complexation procedure to form capsules to the others mentioned before similarities can be observed. The core material is diluted in the coating material ( $\beta$-cyclodextrin) also, but the $\beta$-cyclodextrin needs to be dissolved first in water to form an aqueous solution to then be mixed to the core material. Afterwards, an inclusion complex is formed between $\beta$-cyclodextrin and core material, being the precipitate recovered and dried by conventional means [20].

To eliminate the last required step: capsules drying less amount of water can be utilized to disperse the coating material avoiding additional steps and consequently reducing costs [31].

In spite of important progress to improve economical aspects of the encapsulation by inclusion complexation, such as reducing the water content in the final product, still the relatively expensive price of $\beta$-cyclodextrins and the undesirable release of the formed complex into the mouth are barriers to the industrial development of this technique [3, 21].

\section{ENCAPSULATION TECHNIQUES BASED ON PHYSICAL-CHEMICAL NATURE COMBINATION BETWEEN COATING MATERIAL AND CORE MA- TERIAL}

Some examples of the encapsulation physical-chemical methods are: coacervation, emulsion phase separation, liposome entrapment, etc [8]. Coacervation technique is widely used in the industry, therefore it will be described below while the others techniques will be briefly discussed in the section Advantages and Limitations of the Conventional Encapsulation Methods.

\section{Coacervation}

Coacervation is often regarded as the original method of encapsulation [20]. This technique was the first encapsulation process studied and was initially employed by Green and Scheicher in 1955 to produce capsules for the manufacturing of carbonless copying paper as mentionated before.

Coacervation technique is the separation into two liquid phases in colloidal systems. The phase more concentrated in colloid component is the coacervate (a polymer rich phase) and the other phase is the equilibrium solution (almost polymer free) [32]. Coacervation in aqueous systems is subdivided into simple and complex coacervation.

In the first procedure step, a three-phase system consisting of a liquid manufacturing vehicle phase (solvent), a core material phase, and a coating material phase (formed by one polymer - simple coacervation; by two polymers - complex coacervation) is formed by a direct addition. Afterwards the deposition of the liquid polymer coating around the core material by electrostatic attraction is initialized by controlled physical mixing of the coating material and the core material in the manufacturing vehicle in the liquid phase. After accomplished the deposition it is necessary the stabilization employing toxic chemical agents, such as glutaraldehyde [1].

Due to the ineffective last step required, according Thomasin and coworkers, coacervation is frequently impaired by residual solvents and coacervating agents found in the spheres. Furthermore, it is not well suited for producing spheres in the low size range. Additionally, others drawbacks about this method that is necessary to mention is its very expensive and rather complex process [33].

\section{ADVANTAGES AND LIMITATIONS OF THE CON- VENTIONAL ENCAPSULATION METHODS APPLI- CABLE FOR STABILIZING CAROTENOID PIG- MENTS}

Table 2 summarizes various advantages and limitations of some conventional encapsulation methods applicable for stabilizing unstable carotenoids.

Recently alternative technologies and/or even some small modification as change the conventional organic solvent to "greener solvent" such as supercritical fluids have been evaluated to eliminate some limitations of the conventional encapsulation methods [34].

Advantages as elimination of organic solvents, encapsulation under mild conditions and formation of homogeneus micro-nanocapsules can be achieved using supercritical fluid based-techniques. These techniques could avoid carotenoid fast degradation [35]. Thus, the recent trends in this topic will be discussed.

\section{ENCAPSULATION USING SUPERCRITICAL FLUIDS}

In the recent years, new encapsulation techniques utilizing supercritical fluids have been developed in order to overcome some of the disadvantages of the conventional techniques [49]. Some of these drawbacks are: a) poor control of particle size and morphology; b) degradation of thermo sensitive compounds; c) low encapsulation efficiency; d) low yield [50].

The use of supercritical fluids as phase separating agents has been intensively studied also to minimize the amount of potentially harmful residues in the capsules and most effectively control $[51,52]$.

According to Cocero and coworkers carbon dioxide $\left(\mathrm{CO}_{2}\right)$ is most solvent used for encapsulation purposes due to the supercritical region can be achieved at moderate pressures and temperatures $(\mathrm{Tc}=304.2 \mathrm{~K}, \mathrm{Pc}=7.38 \mathrm{MPa})$; therefore, working with supercritical $\mathrm{CO}_{2}$ it is possible to carry out the process at near-ambient temperatures, avoiding the degradation of thermolabile substances [53].

Several encapsulation processes that use supercritical fluids have been developed. These processes can be classified according to the role of the supercritical fluid in the process: solvent [Rapid Expansion of Supercritical Solutions (RESS)]; Supercritical Solvent Impregnation (SSI), solute [Particles from Gas Saturated Solutions (PGSS)] or antisolvent [Supercritical Anti-Solvent (SAS); Supercritical Fluid Extraction of Emulsions (SFEE)] [54].

Given that the two most commonly encapsulation methods employed using supercritical fluids are the Rapid Expansion of Supercritical Solution (RESS) and the Supercritical Anti-Solvent (SAS) methods [54], particular consideration will be given to these techniques. Furthermore the potential application of supercritical fluids in the micro-nanoencapsulation technology with emulsions called by the literature of Supercritical Fluid Extraction of Emulsions (SFEE) will be presented. 
Table 2. Advantages and Limitations of Some Conventional Encapsulation Methods Applicable for Stabilizing Unstable Carotenoids

\begin{tabular}{|c|c|c|c|c|}
\hline $\begin{array}{l}\text { Conventional } \\
\text { Encapsulation } \\
\text { Method }\end{array}$ & Principle & Advantages & Limitations & References \\
\hline Spray Drying & $\begin{array}{l}\text { Dispersion of the core material in a en- } \\
\text { trapment material, followed by atomization } \\
\text { and spraying of the mixture in a hot air } \\
\text { desiccant into a chamber }\end{array}$ & $\begin{array}{l}\text { Low process cost; wide } \\
\text { choice of coating material; } \\
\text { good encapsulation effi- } \\
\text { ciency; good stability of the } \\
\text { finished product; possibility } \\
\text { of large-scale production in } \\
\text { continuous mode }\end{array}$ & $\begin{array}{l}\text { Can degradate highly tempera- } \\
\text { ture-sensitive compounds; } \\
\text { control of the particle size is } \\
\text { difficult; yields for small } \\
\text { batches are moderate }\end{array}$ & $\begin{array}{c}{[19,20,22,} \\
23]\end{array}$ \\
\hline $\begin{array}{c}\text { Spray } \\
\text { Cooling/Chilling }\end{array}$ & $\begin{array}{c}\text { The same of the spray drying differing only } \\
\text { that the air desiccant is cold }\end{array}$ & $\begin{array}{l}\text { Temperature-sensitive com- } \\
\text { pounds can be encapsulated }\end{array}$ & $\begin{array}{c}\text { Difficult control of the particle } \\
\text { size; moderate yields for small } \\
\text { batches; special handling and } \\
\text { storage conditions can be re- } \\
\text { quired }\end{array}$ & {$[21,23,36]$} \\
\hline Simple Extrusion & $\begin{array}{l}\text { Forcing a core material in a molten wall } \\
\text { material mass through a die (laboratory } \\
\text { scale) or a series of dies of a desired cross- } \\
\text { section into a bath of desiccant liquid. The } \\
\text { coating material hardens on contacting } \\
\text { liquids, entraping the active substances }\end{array}$ & $\begin{array}{l}\text { The material is totally sur- } \\
\text { rounded by the wall material; } \\
\text { any residual core is washed } \\
\text { from the outside; it is a rela- } \\
\text { tively low-temperature en- } \\
\text { trapping method }\end{array}$ & $\begin{array}{l}\text { The capsule must be separated } \\
\text { from the liquid bath and dried; } \\
\text { is difficult to obtain capsules in } \\
\text { extremely viscous carrier mate- } \\
\text { rial melts }\end{array}$ & {$[3,12,22,26]$} \\
\hline Centrifugal Extrusion & $\begin{array}{l}\text { Similar of simple extrusion differing that } \\
\text { the core material and coating material form } \\
\text { a unified jet flow only at the end through a } \\
\text { nozzle with a coaxial opening (co- } \\
\text { extrusion) by centrifugal force }\end{array}$ & The same of simple extrusion & The same of simple extrusion & [24] \\
\hline Ionic Gelation & $\begin{array}{l}\text { Coating material with dissolved core mate- } \\
\text { rial is extruded as drops within an ionic } \\
\text { solution. The capsules are formed by ionic } \\
\text { interaction }\end{array}$ & $\begin{array}{c}\text { Organic solvents and extreme } \\
\text { condions of temperature and } \\
\text { pH are avoided }\end{array}$ & $\begin{array}{l}\text { Mainly used on a laboratory } \\
\text { scale; the capsules, in general, } \\
\text { have high porosity which pro- } \\
\text { motes intensive burst }\end{array}$ & {$[37,38]$} \\
\hline Thermal Gelation & $\begin{array}{l}\text { The principle is almost the same of ionic } \\
\text { gelation' principle, nonetheless there is no } \\
\text { necessity of an ionic solution to form a } \\
\text { gelled drop, the gelation is only due to } \\
\text { thermal parameters }\end{array}$ & The same of ionic gelation & The same of ionic gelation & {$[37,38]$} \\
\hline Fluidized Bed Coating & $\begin{array}{l}\text { This technique relies upon by nozzle spray- } \\
\text { ing the coating material into a fluidized bed } \\
\text { of core material in a hot environment }\end{array}$ & $\begin{array}{l}\text { Low cost process; it allows } \\
\text { specific capsule size distribu- } \\
\text { tion and low porosities into } \\
\text { the product }\end{array}$ & $\begin{array}{l}\text { Degradation of highly tempera- } \\
\text { ture-sensitive compounds }\end{array}$ & {$[28,39]$} \\
\hline $\begin{array}{l}\text { Lyophilization/Freeze } \\
\text { Drying }\end{array}$ & $\begin{array}{c}\text { The entrapment occurs by lyophilization of } \\
\text { an emulsion solution contaning a core } \\
\text { material and a coating material }\end{array}$ & $\begin{array}{c}\text { Thermosensitive substances } \\
\text { that are unstable in aqueous } \\
\text { solutions may be efficiently } \\
\text { encapsulated by this tech- } \\
\text { nique }\end{array}$ & $\begin{array}{l}\text { Long processing time; expen- } \\
\text { sive process costs; expensive } \\
\text { storage and transport of the } \\
\text { capsules }\end{array}$ & [40] \\
\hline Inclusion Complexation & $\begin{array}{c}\text { Particular apolar molecules are entrapped } \\
\text { through a hydrophobic interaction inside } \\
\text { the } \beta \text {-Cyclodextrin cavity replacing water } \\
\text { molecules }\end{array}$ & $\begin{array}{c}\text { Very efficient to protect } \\
\text { unstable and high added } \\
\text { value apolar compounds such } \\
\text { as flavours }\end{array}$ & $\begin{array}{l}\text { Encapsulation restricted to } \\
\text { apolar compounds with a suit- } \\
\text { able molecular dimensions; } \beta \text { - } \\
\text { cyclodextrin price is expensive; } \\
\text { frequently undesirable release } \\
\text { of the formed complex }\end{array}$ & {$[3,21,28,30]$} \\
\hline Emulsion Polymerization & $\begin{array}{c}\text { Core material is dissolved into polymeriza- } \\
\text { tion sollution. The monomers are polymer- } \\
\text { ized to form capsules in an aqueous solu- } \\
\text { tion }\end{array}$ & $\begin{array}{l}\text { Micro-nanocapules with } \\
\text { narrow size distribution can } \\
\text { be obtained }\end{array}$ & $\begin{array}{l}\text { Difficult control of the capsule } \\
\text { formation (polymerization) }\end{array}$ & {$[41,42]$} \\
\hline
\end{tabular}


Table 2. contd....

\begin{tabular}{|c|c|c|c|c|}
\hline $\begin{array}{l}\text { Conventional } \\
\text { Encapsulation } \\
\text { Method }\end{array}$ & Principle & Advantages & Limitations & References \\
\hline $\begin{array}{c}\text { Emulsion Phase Separa- } \\
\text { tion }\end{array}$ & $\begin{array}{l}\text { The core material is added in the polar or } \\
\text { apolar layer of an oil-in-water emulsion - } \\
\text { O/W or water-in-oil - W/O emulsion. The } \\
\text { emulsions are prepared using a surfactant }\end{array}$ & $\begin{array}{l}\text { Polar, non-polar (apolar), and } \\
\text { amphiphilic can be incorpo- } \\
\text { rated; emulsions can either be } \\
\text { used directly in their "wet" } \\
\text { state }\end{array}$ & $\begin{array}{l}\text { Instable when exposed to envi- } \\
\text { ronmental stresses, such as } \\
\text { heating, drying, etc; limited } \\
\text { number of emulsifiers that can } \\
\text { be used }\end{array}$ & {$[45,46]$} \\
\hline
\end{tabular}

\section{RAPID EXPANSION OF SUPERCRITICAL SOLU- TION (RESS) METHOD}

In the RESS method the solution of core material plus coating material is solubilized in a supercritical fluid and the solution is expanded rapidly through a nozzle. Thus, the solvent power of supercritical fluid dramatically decreases and eventually occurs the co-precipitation of both substances [55]. According to Mishima and Matsuyama (2006) it is difficult to disperse the core material homogenously in the coating material in the absence of surfactants or a high shear condition in the supercritical $\mathrm{CO}_{2}[56]$. In order to avoid this homogeneity problem mechanical agitation or ultrasonic irradiation apparatus have been added into the high-pressure vessel [56, 57].

RESS technique is environmental friendly because the capsule is completely solvent free. Unfortunately, most wall materials exhibit little or no solubility in supercritical fluids, limiting this technique to restrict applications [55].

To overcome the low solubility limitation of the wall materials in $\mathrm{CO}_{2}$, alternative organic supercritical solvents has been employed. Another procedure by modification the original RESS process has been carried out also for eliminating this solubility problem. This modified process has been named by RESS-non-solvent process (RESS-N). In this process, a liquid antisolvent for the coating material is used as a cosolvent for improving the solubility in the supercritical fluid [58].

According to Cocero and coworkers besides the solubility limitations, another major problem of RESS techniques is the difficulty to control the morphology and loading of the capsules [53].

\section{SUPERCRITICAL ANTI-SOLVENT (SAS) METHOD}

The encapsulation by SAS technique, also called by Gas Anti-Solvent (GAS) method, is based on the same simple principle of RESS method whereby a core material and a carrier are co-precipitated together. In SAS method the antisolvent (non-solvent) property of supercritical carbon dioxide $\left(\mathrm{CO}_{2}\right)$ is used, since most wall materials and core material are not soluble in supercritical $\mathrm{CO}_{2}$ [49].

The basic principle of the SAS method is based on a rapid decrease in the solubilization power of a solvent by addition of a second solvent as antisolvent. Upon mixing, the supercritical fluid (antisolvent) saturates the conventional liquid solvent and depletes it by extraction. Particle size distribution can be partially controlled by adjusting the values of temperature, pressure and composition. The high viscosity of the coating material- $\mathrm{CO}_{2}$ solutions during atomization or the solvent extraction process, generally, leads to inconsistency of the particle size, strong particle agglomeration, and also incomplete encapsulation [59].

Another disadvantage of the supercritical antisolvent process is the difficulty to remove the remaining solvent completely because the process generally carries out in a batch discontinuous process [59].

In order to overcome some of the disadvantages mentioned above Chattopadhyay an coworkers have developed and patented a new encapsulation method called Supercritical Fluid Extraction of Emulsions (SFEE). Essentially this method is combines the flexibility of particle engineering using different emulsion systems with the efficiency of large scale, continuous extraction ability, provided by supercritical fluids [52].

According to Perrut and coworkers the application of supercritical fluids in the encapsulation technology with emulsions appears as a natural decision to avoid the main problems of each technology separately. Emulsion phase separation, emulsion polymerization and others emulsion techniques usually involve large quantities of organic solvents, and the removal of them involves additional separation proc- 
Table 3. Articles Published in Journals Indexed in the Web of Science and Scopus Databases About Carotenoid Encapsulation Using Supercritical Fluids

\begin{tabular}{|c|c|c|c|}
\hline & Article Title & Encapsulation Method & References \\
\hline 1 & Carotenoid processing with supercritical fluids & SAS and SEDS & [66] \\
\hline 2 & $\begin{array}{l}\text { Precipitation of } \beta \text {-carotene and PHBV and co-precipitation from SEDS technique using } \\
\text { supercritical } \mathrm{CO}_{2}\end{array}$ & SEDS & {$[50]$} \\
\hline 3 & $\begin{array}{l}\text { Precipitation of lutein and co-precipitation of lutein and poly-lactic acid with the } \\
\text { supercritical anti-solvent process }\end{array}$ & SAS & [68] \\
\hline 4 & $\begin{array}{c}\text { Co-precipitation of } \beta \text {-carotene and polyethylene glycol with compressed } \mathrm{CO}_{2} \text { as an } \\
\text { antisolvent: effect of temperature and concentration }\end{array}$ & SAS & [69] \\
\hline 5 & $\begin{array}{l}\text { Production of natural carotene-dispersed polymer microparticles by SEDS-PA } \\
\text { co-precipitation }\end{array}$ & SEDS & [64] \\
\hline 6 & Co-precipitation of carotenoids and bio-polymers with the supercritical anti-solvent process & SAS & [17] \\
\hline 7 & Requirements for non-food applications of pea proteins. A Review & SFEE & [35] \\
\hline
\end{tabular}

ess and the use of high temperatures. On the other hand, supercritical fluids regularly are not able to produce capsules below the micrometer range or the products obtained present agglomeration problems [60].

According Cocero and coworkers the difference from SAS processes and the SFEE, among others, is that an emulsion containing the core materials to be precipitated dissolved in its dispersed phase (conventional liquid solvent) is injected instead of injecting a simple solution of the core materials. Effectively during the "extraction" (encapsulation) it can be expected that first the droplets of the disperse phase become saturated by $\mathrm{CO}_{2}$, and then the solvent is extracted by $\mathrm{CO}_{2}$ from them. Therefore during the saturation with $\mathrm{CO}_{2}$ each droplet behaves as a miniature SAS Anti-Solvent precipitator [53].

\section{ENCAPSULATION OF CAROTENOID PIGMENTS USING SUPERCRITICAL FLUIDS}

Due to the presented potential advantages of the encapsulation process using supercritical fluids for carotenoid encapsulation these techniques seem to be more appropriate.

In a careful literature survey in Web of Science and Scopus databases it was found several articles about carotenoid pigments encapsulation. But, more specifically about carotenoid encapsulation using supercritical fluids this amount was reduced intensively to only 7 articles (Table $\mathbf{3}$ ).

Conventional encapsulation techniques such as spray drying and inclusion complexation were the most common methods evaluated for encapsulating carotenoids. Other studies, aiming indirectly at the development of alternative technologies towards encapsulating carotenoids in wall materials using supercritical technology were found, but the amount was still scarce. Even though, a significant increase in this amount could be observed since 2006 until now (Fig. 1). Fig. 1 also shows that approximately $80 \%$ of the articles that aims for developing supercritical fluids based technologies towards encapsulating carotenoids have been published in the last 4 years.

Analyzing the literature about the evolution of encapsulating technologies carotenoids using supercritical fluids

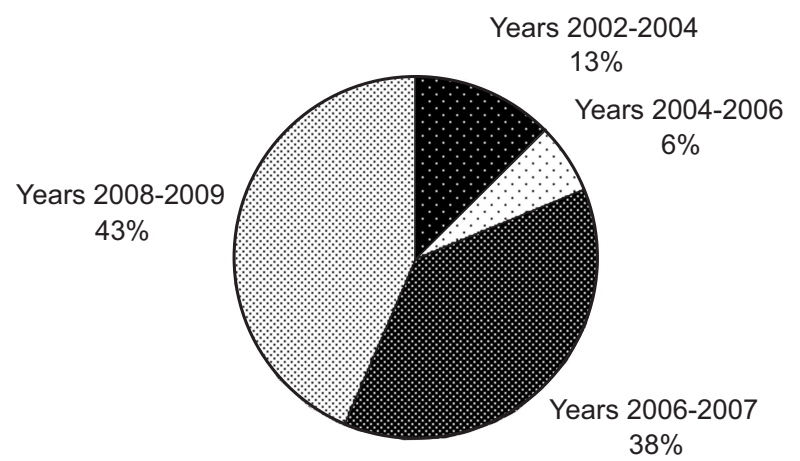

Fig. (1). Distribution of the published articles that aims for developing supercritical fluids based technologies towards encapsulating carotenoids.

could be observed that it can be divided in four sequencial parts. 1) First, a complex study of the precipitation of many solutes, including carotenoids, from supercritical fluids by rapid expansion (RESS process) was done in order to avoid thermal decomposition that generally occurs by milling process [61]; 2) After that, carotenoid precipitation from liquid solvents, with dissolution by high-pressure or supercritical $\mathrm{CO}_{2}$ as an antisolvent to create supersaturation (GAS or SAS processes, respectively) was evaluated as a crystallization process [62]; 3) In this part, the co-precipitation of many solutes such as carotenoids and coating materials towards protect and stabilize them was extensively studied [63, 64]; 4) Finally, carotenoid encapsulation by RESS, GAS and SAS techniques have been better studied (being in some cases also successfully scaled up) and other techniques such as the novel Solution Enhanced Dispersion by Supercritical (SEDS) fluids, based on the principle of SAS, has been applied (Table 3) [64-67].

In SEDS process, a nozzle with two coaxial passages allows introducing supercritical $\mathrm{CO}_{2}$ and a solution with core and coating materials into the particle formation vessel where pressure and temperature are controlled. The high velocity of supercritical $\mathrm{CO}_{2}$ allows breaking up the solution into very small droplets since that the velocity is set up to 
extract the solvent from the solution (SAS principle) at the same time as it meets and disperses the solution [65].

The use of a coaxial nozzle for encapsulation purposes is not new. In this review paper was demonstrated that in extrusion coating method the same nozzle type was used to the same purpose [24]. Thus, it can be seen that the recent encapsulation methods are based on modifying conventional techniques.

\section{CONCLUSION}

This review paper has demonstrated the potentiality of the use of supercritical fluids based encapsulation to protect and stabilize unstable pigments. Among the advantages are: form micro- or even nanoparticles with narrow particle distribution, reduce or even eliminate the residual organic solvent in the product, and control product quality.

Nowadays alternative technologies based on small modification as change the conventional organic solvent to "greener solvent" such as supercritical fluids have been evaluated successfully to eliminate some limitations of the conventional encapsulation methods.

\section{ACKNOWLEDGEMENTS}

The authors are grateful to CNPq for the doctorate fellowship (141894/2009-1) and for the financial support (580401/2008-1).

\section{REFERENCES}

[1] K.G.H. Desai and H.J. Park, "Recent developments in microencapsulation of food ingredients", Dry. Technol., vol. 23, pp.1361-1394, 2005.

[2] A. Fernandez and J.M.L. Torres-Giner, "Novel route to stabilization of bioactive antioxidants by encapsulation in electrospun fibers of zein prolamine", Food Hydrocoll., vol. 23, pp. 1427-1432, 2009.

[3] B.F. Gibbs, S. Kermasha, I. Alli and C.N. Mulligan, "Encapsulation in the food industry: a review", Intern. J. Food Sci. Nutr., vol. 50, pp. 213-224, 1999.

[4] H. Jizomoto, E. Kanaoka, K. Sugita and K. Hirano, "Gelatin-acacia microcapsules for trapping micro oil droplets containing lipophilic drugs and ready disintegration in the gastrointestinal tract", Pharm. Res., vol. 10(8), pp. 115-122, 1993.

[5] C. Kibry, "Microencapsulation and controlled delivery of food ingredients", J. Food Sci. Technol., vol. 5, pp. 74-78, 1991.

[6] A. Madene, M. Jacquot, J. Scher and S. Desobry, "Flavour encapsulation and controlled release - a review", Intern. J. Food Sci. Technol., vol. 41, pp. 1-21, 2006.

[7] R.M.Corrêa, "Produção de micropartículas por gelificação iônica para alimentação de larvas de peixe: estudos em sistema - modelo com inclusão de micropartículas lipídicas ou emulsão lipídica e testes in vivo", Ph.D. Thesis, Univeristy of Campinas, Campinas, SP, Brazil, 2008.

[8] L.S. Jackson and K. Lee, "Microencapsulation and the food industry”, LWT - Food Sci. Technol., vol. 24, pp. 289-297, 1991.

[9] D.T. Santos and M.A.A. Meireles, "Jabuticaba as a source of functional pigments". Phycog Rev. vol. 3(5), pp. 127-132, 2009.

[10] W. Miki, "Biological functions and activities of carotenoids", Pure Appl. Chem., vol. 63, pp. 141-146, 1991.

[11] F. Shahidi, and X.Q. Han, "Encapsulation of food ingredients", Crit. Rev. Food Technol., vol. 33(6), pp. 501-504, 1993.

[12] L. Gouveia and J. Empis, "Relative stabilities of microalgal carotenoids in microalgal extracts, biomass and fish feed: effect of storage conditions", Innov. Food Sci. Emerg. Technol., vol. 4, pp. 227233, 2003.

[13] P. Robert, R.M. Carlsson, N. Romero and L. Masson, "Stability of spray-dried encapsulated carotenoid pigments from rosa mosqueta (Rosa rubiginosa) oleoresin", J. Am. Oil Chem. Soc., vol. 80(11), 2003.

[14] D.J. McClements, E.A. Decker, Y. Park and J. Weiss, "Structural design principles for delivery of bioactive components in nutraceu- ticals and functional foods", Crit. Rev. Food Sci. Nutr., vol. 49, pp. 577-606, 2009.

[15] K. Selim, M. Tsimidou and C.G. Biliaderis, "Kinetic studies of degradation of saron carotenoids encapsulated in amorphous polymer matrices", Food Chem., vol. 71, pp. 199-206, 2000.

[16] A. Martín, F. Mattea, L. Gutierrez, F. Miguel and M.J. Cocero, "Co-precipitation of carotenoids and biopolymers with the supercritical anti-solvent process", J. Supercrit. Fluids, vol. 41, pp.138147, 2007.

[17] C. Peniche, W. Argüelles-Monal, H. Peniche and N. Acosta, "Chitosan: an attractive biocompatible polymer for microencapsulation”, Macromol. Biosci., vol. 3, pp. 511-520, 2003.

[18] S. Freitas, H.P. Merkle and B. Gander, "Microencapsulation by solvent extraction/evaporation: reviewing the state of the art of microsphere preparation process technology", J. Control. Release, vol. 102, pp. 313-332, 2005.

[19] J.D. Dziezak, "Microencapsulation and encapsulation ingredients", Food Technol., vol. 42, pp. 136-151, 1988.

[20] S.J. Risch, "Encapsulation: overview of uses and techniques", In Encapsulation and Controlled Release of Food Ingredient, S.J. Rish and G. A. Reineccius, Eds. Washington, DC, American Chemical Society, 1995.

[21] S. Gouin, "Microencapsulation: industrial appraisal of existing technologies and trends", Trends Food Sci. Technol., vol. 15, pp. 330-347, 2004

[22] G. A. Reineccius, "Flavor encapsulation". Food Rev. Intern., vol. 5, pp. 147-176, 1989.

[23] P. Johansen, H.P. Merkle and B. Gander, "Technological considerations related to the up-scaling of protein microencapsulation by spray-drying", Eur. J. Pharm. Biopharm., vol. 50, pp. 413-417, 2000.

[24] W. Schlameus, "Centrifugal extrusion encapsulation”, In Encapsulation and Controlled Release of Food Ingredient, S.J. Rish and G. A. Reineccius, Eds. Washington, DC, American Chemical Society, 1995.

[25] D.J. Wampler, "Flavor encapsulation: a method for providing maximum stability for dry flavor systems", Cereal Foods World. vol. 37, pp. 817-820, 1992.

[26] S.J. Risch, "Encapsulation of flavours by extrusion", In Flavour Encapsulation, S.J. Rish and G. A. Reineccius, Eds., Washington, DC, American Chemical Society, 1988, pp. 103-109.

[27] I. Sondi, T.H. Fedynyshyn, R. Sinta and E. Matijevic, "Encapsulation of nanosized silica by in situ polymerization of tert-butyl acrylate monomer", Langmuir, vol. 16, pp. 9031-9034, 2000.

[28] J. Uhlemann, B. Schleifenbaum and H.J. Bertram, "Flavor encapsulation technologies: an overview including recent developments", Perfumer Flavorist, vol. 27, pp. 52-61, 2002.

[29] I., Mourtzinos, F. Salta, K. Yannakopoulou, A. Chiou and V.T. Karathanos, "Encapsulation of olive leaf extract in $\beta$-cyclodextrin", J. Agri. Food Chem., vol. 55, pp. 8088-8094, 2007.

[30] J. Szejtli, "Introduction and general overview of cyclodextrin chemistry", Chem. Rev., vol. 98, pp. 1743-1753, 1998.

[31] J.S. Pagington, " $\beta$-Cyclodextrin and its uses in the flavour industry" In Developments in Food Flavours, G.G. Birch and M.G. Lindley, Eds, London, Elsevier Applied Science, 1986.

[32] C.G. Kruif, F. Weinbrecka and R. Vriesc, "Complex coacervation of proteins and anionic polysaccharides", Curr. Opin. Colloid Interface Sci., vol. 9, pp. 340-349, 2004.

[33] C. Thomasin, P. Johansen, R. Alder, R. Bemsel, G. Hottinger, H. Altorfer, A.D. Wright, E. Wehrli, H.P. Merkle and B. Gander, "A contribution to overcoming the problem of residual solvents in biodegradable microspheres prepared by coacervation" Eur. J. Pharm. Biopharm., vol. 42, pp. 16-24, 1996.

[34] G.P. Blanch, M.L.R. Castillo, M.M. Caja, M. Pérez-Méndez and S. Sánchez-Cortés, "Stabilization of all-trans-lycopene from tomato by encapsulation using cyclodextrins" Food Chem., vol. 105, pp. 1335-1341, 2007.

[35] L.A. De Graaf, P.F.H. Harmsen, J.M. Vereijken and M. Mönikes, "Requirements for non-food applications of pea proteins, a review", J. Food Nahrung, vol. 45(6), pp. 408-411, 2001.

[36] A. H. Taylor, "Encapsulation systems and their applications in the flavor industry", Food Flavour Ingredient Process Packaging, vol. 4, pp. 48-52, 1983.

[37] C. Heinzen, "Microencapsulation solve time dependent problems for foodmakers", Eur. Food Drink Rev., vol. 3, pp. 27-30, 2002. 
[38] R.G. Willaert and G.V. Baron, "Gel entrapment and microencapsulation: methods, applications and engineering principles", Rev. Chem. Eng., vol. 12, pp. 5-205, 1996.

[39] K.J. Chua and S.K. Chou, "Low-cost drying methods for developing countries", Trends Food Sci. Technol., vol. 14, pp. 519-528, 2003.

[40] M. Jacquot and M. Pernetti, "Spray coating and drying processes", In Cell Immobilization Biotechnology, U. Nedovic and R. Willaert, Eds, Dordrecht, Kluwer Academic Publishers, 2003, pp. 343-356.

[41] N. Behan, C. Birkinshaw and N. Clarke, "A study of the factors affecting the formation of poly(n-butylcyanoacrylate) nanoparticles", In International Symposium on Controlled Release of Bioactive Materials, 1999, pp. 1134-1135.

[42] T.K.M. Mabela, J.H. Poupaert, P. Dumont, and A. Haemers, "Development of poly(dialkyl methylidenemalonate) nanoparticles as drug carriers", Int. J. Pharm., vol. 92, pp. 71-79, 1993.

[43] C. Sanchez and D. Renard, "Stability and structure of proteinpolysaccharide coacervates in the presence of protein aggregates", Intern. J. Pharm., vol. 242, pp. 319-324, 2002.

[44] C.J.F. Arneodo, "Microencapsulation by complex coacervation at ambient temperature", F. R. 2, 732, 240, 1996.

[45] D.J. McClements, Food Emulsions: Principles, Practice and Techniques. Boca Raton, FL, CRC Press, 2005.

[46] D.J. McClements and E.A. Decker, "Lipid oxidation in oil-inwater emulsions: impact of molecular environment on chemical reactions in heterogeneous food systems" J. Food Sci., vol. 65(8), pp. 1270$1282,2000$.

[47] C.J. Kirby and G. Gregoriadis, "A simple procedure for preparing liposomes capable of high encapsulation efficiency under mild conditions", In Liposome Technology, G. Gregoriadis, Ed, Boca Raton, FL, CRC Press, 1984.

[48] S. Zheng, H. Alkan-Onyuksel, R.L. Beissinger and D.T. Wasan, "Liposome microencapsulation without using any organic solvent", J. Dispers. Sci. Technol., vol. 20, pp. 1189-1203, 1999.

[49] P. Chattopadhyay, R. Huff and B.Y. Shekunov, "Drug encapsulation using supercritical fluid extraction of emulsions", J. Pharm. Sci., vol. 95, pp. 667-679, 2006.

[50] E. Franceschi, A.M. Cesaroa, M. Feiten, S.R.S. Ferreira, C. Dariva, M.H. Kunita, A.F. Rubira, E.C. Muniz, M.L. Corazza and J.V. Oliveira, "Precipitation of $\beta$-carotene and PHBV and co-precipitation from SEDS technique using supercritical $\mathrm{CO}_{2}$ ", $J$. Supercrit. Fluids., vol. 47, pp. 259-269, 2008.

[51] J. Jung and M. Perrut, "Particle design using supercritical fluids: literature and patent survey", J. Supercrit. Fluids., vol. 20, pp. 179219, 2001.

[52] P. Chattopadhyay, B.Y. Shekunov, J.S. Seitzinger and R.W. Huff, "Particles from supercritical fluid extraction of emulsion", $U . S$. Patent 004,862, 2004

[53] M.J. Cocero, A. Martín, F. Mattea and S. Varona, "Encapsulation and co-precipitation processes with supercritical fluids: fundamen- tals and applications", J. Supercrit. Fluids., vol. 47, pp. 546-555, 2009.

[54] A. Martín and M.J. Cocero, "Micronization processes with supercritical fluids: Fundamentals and mechanisms", Adv. Drug Deliv. Rev., vol. 60(3), pp. 339-350, 2008.

[55] K.S. Soppimath, T.M. Aminabhavia, A.R. Kulkarnia and W.E. Rudzinski, "Biodegradable polymeric nanoparticles as drug delivery devices", J. Control. Release, vol. 70, pp. 1-20, 2001.

[56] K. Mishima and K. Matsuyama, "Method for preparing composite fine particles", Japan Patent 057,374, 2006.

[57] E. Mathiowitz, L. Kundakovic, A.P. Morello, M.W. Harrison and J.J. Reineke, "Particles with high uniform loading of nanoparticles and methods of preparation thereof", U. S. patent 054,874, 2008.

[58] D.D. Yeo and E. Kiran, "Formation of polymer particles with supercritical fluids: A review", J. Supercrit. Fluids., vol. 34, pp. $287-$ 308, 2005.

[59] K. Mishima, "Biodegradable particle formation for drug and gene delivery using supercritical fluid and dense gas", Adv. Drug Deliv. Rev., vol. 60 pp. 411-432, 2008.

[60] M. Perrut, J. Jung and F. Leboeuf, "Method for obtaining particles from at least a water soluble product" U. S. patent 110,871, 2004.

[61] C.J. Chang and A.D. Randolph, "Precipitation of microsize organic particles from supercritical fluids", AIChE J., vol. 35(11), pp. 1876-1882, 1989.

[62] A.D. Randolph, "Separation of $\beta$-carotene mixtures precipitated from liquid solvents with high-pressure $\mathrm{CO}_{2} "$, Biotechnol. Progress, vol. 7 (3), pp. 275-278, 1991.

[63] H. Ksibi and P. Subra, "Powder coprecipitation by the RESS process", Adv. Powder, vol. 7(1), pp. 21-28, 1996.

[64] C. Domingo, A. Vega, M.A. Fanovich, C. Elvira and P. Subra, "Behavior of poly(methyl methacrylate)-based systems in supercritical $\mathrm{CO}_{2}$ and $\mathrm{CO}_{2}$ plus cosolvent: Solubility measurements and process assessment", J. Appl. Polymer Sci., vol. 90(13), pp. 36523659, 2003.

[65] W. He, Q. Suo, H. Hong, A. Shan, C. Li, Y. Huang, Y. Li and M. Zhu, "Production of natural carotene-dispersed polymer microparticles by SEDS-PA co-precipitation", J. Mat. Sci., vol. 42(10), pp. 3495-3501, 2007.

[66] F. Mattea, A. Martín and M.J. Cocero, "Carotenoid processing with supercritical fluids", J. Food Eng., vol. 93(3), pp. 255-265, 2009.

[67] E. Weidner, "High pressure micronization for food applications", J. Supercrit. Fluids, vol. 47(3), pp. 556-565, 2009.

[68] F. Miguel, A. Martín, F. Mattea and M.J. Cocero, "Precipitation of lutein and co-precipitation of lutein and poly-lactic acid with the supercritical anti-solvent process", Chem. Eng. Processing: Process Intensification, vol. 47(9-10), pp. 1594-1602, 2008.

[69] F. Mattea, A. Martín and M.J. Cocero, "Co-precipitation of betacarotene and polyethylene glycol with compressed $\mathrm{CO}_{2}$ as an antisolvent: Effect of temperature and concentration", Ind. Eng. Chem. Res., vol. 47(11), pp. 3900-3906, 2008.

(C) Santos and Meireles; Licensee Bentham Open.

This is an open access article licensed under the terms of the Creative Commons Attribution Non-Commercial License (http://creativecommons.org/licenses/by-nc/3.0/) which permits unrestricted, non-commercial use, distribution and reproduction in any medium, provided the work is properly cited. 